\title{
Reducing the Social Assistance Benefits of Refugees Affect Their Res- idential Integration? Evidence from a Natural Experiment
}

\author{
Frederik Juhl Jørgensen \\ Department of Political Science, Aarhus University \\ fj@ps.au.dk
}

\begin{abstract}
I exploit quasi-random assignment of social assistance benefits induced by a major Danish reform to obtain credible causal evidence for the effect of social assistance reductions on residential integration (i.e., the extent to which refugees settle among natives). Comparing otherwise similar refugees, I find that reducing the benefits of refugees markedly deteriorated their residential integration especially in the long-term. In particular, refugees' residential segregation increased by about 28 percent as a consequence of the benefit reductions. I show that this effect most likely runs through a deprivation mechanism, where refugees live on a subsistence minimum that significantly limit their location choice. Moreover, I demonstrate that the overall effect is concentrated among the low educated who face the largest resource constraints, most marginalization, and have the worst chances of integrating into the host society at the outset.
\end{abstract}

Key words: Residential integration, assistance benefits, natural experiment 


\section{Introduction}

Following sharp increases in their refugee populations, policy-makers of refugee-receiving democracies are confronting a fundamental challenge: How to develop policies that foster refugee integration, while at the same time being supported by domestic voters. Addressing an increasing worry about abuse of the host country's welfare system has led many countries to implement reforms that reduce social transfer levels. However, we know relatively little about how these policies affect the integration of refugees. One view—often advanced by parties on the right—argues that such policies incentivize individual refugees to get off welfare, find employment, and thereby promote labor market integration as a first step toward integration into the host society more broadly. The contrasting view — often advanced by parties on left — argue that they pose a barrier to the integration of refugees because reductions mainly creates a large underprivileged group who is denied an equal share of the society's goods.

In this article, I contribute to this debate by studying refugees' location choice in response to a large-scale reform of the Danish social assistance system that lowered assistance benefits by up to 50 percent for new refugees (Andersen 2007). In particular, I ask the question: Does benefit reductions hamper refugees' residential integration (i.e., the extent to which refugees settle among natives). Focusing on residential integration as a key measure of refugee integration is warranted both theoretically and empirically. Theoretically, ethnic residential concentration is commonly recognized as an impediment on refugees' integration process because it is perceived to slow down their acquisition of country-specific human capital, including language skills and knowledge about the host country (Damm and Rosholm 2010). Empirically, ethnic concentration can very well be expected to go hand-in-hand with integration failure in other dimensions of refugee integration. Previous research have, for example, shown ethnic concentration to be negatively correlated with labor market outcomes (Cutler and Glaeser 1997; Van der Klaauw and Van Ours 2003; Thomas and Moye 2015), 
educational achievement (Cutler and Glaeser 1997; Burdick-Will et al. 2011), and health (Kershaw and Albrecht 2015; White and Borrell 2011; Yang and Matthews 2015).

Altogether, the study contributes to two separate literatures. First, there is the literature about the effects of benefit reductions on refugee integration. This literature has mainly focused on short-term economic effects of reducing refugees' benefits (e.g. Rosholm and Vejlin 2010; Huynh, Schultz-Nielsen, and Tranæs 2007). From a policy standpoint, this is concerning because policymakers may not be fully aware of the consequences of their decisions when designing the policies. I contribute to this literature by focusing on an important alternative outcome-residential integration — and analyzing short- as well as long-term reduction effects.

Second, there is the longstanding literature on the causes of residential choice and ethnic residential segregation. The explanations of this literature can broadly be categorized into three dominant theoretical perspectives: Socioeconomic status (e.g. Borjas 1998; Crowder and Krysan 2016; Sager 2012), individual preferences (Schelling 1971, 1969; Clark 1991), and discrimination (South and Crowder 1998; Charles 2003; Crowder and Krysan 2016). The key problem faced by most studies on the causes of residential segregation is that an individual's socioeconomic status, preferences, or experience with discrimination is not random. As a result, most studies suffer from traditional problems concerning omitted variable bias. I contribute to this literature by leveraging quasi-experimental variation in benefits and thereby providing new causal estimates for the effect of benefit reductions on residential integration. It is important to note, that the study is not designed to reject prior research on residential choice, but rather to get better causal leverage on specific mechanisms, while controlling for the factors that previous researchers have identified as drivers of residential choice.

In particular, I exploit the Danish start help that implied that refugees who obtained residency after July 12002 were only eligible for reduced assistance (the so-called "start help"), whereas refugees who obtained residency before this cutoff were eligible for regular assistance 
(Rosholm and Vejlin 2010; Huynh, Schultz-Nielsen, and Tranæs 2007). The reductions were substantial. Thus, depending on household composition, start help was up to 50 percent lower than regular assistance and de facto placed new refugees on assistance levels that were at or below a subsistence minimum in Denmark (Andersen 2007). My data are based on Danish national registers and combine information on the exact date of residency with information on the individual's residential surroundings to provide direct estimates for the short- and long-term effects of lower assistance benefits. These unique data allow me to exploit the discontinuity in benefits in a regression discontinuity (RD) design. I show that the design is robust across various identification tests and robustness checks that corroborates the design-based identifaction.

The study yields three main results. First, the benefit reductions markedly hampered refugees' residential integration especially in the long-term: Compared to otherwise similar refugees, start help refugees were settled in neighborhoods with an ethnic concentration that was about 28 percent higher in the long-term. These overall results are striking as they show that two refugees who are identical in terms of their background characteristics but separated by only a few days with regard to residency settle in remarkably different residential surroundings. Second, I show that this effect most likely runs through a deprivation mechanism: Start help refugees live on a subsistence minimum that significantly limit their location choice. Third, consistent with this mechanism, I demonstrate that the effect is driven mostly by the low educated: The reductions raise long-term ethnic concentration about 50 percent among this group.

\section{Does Lower Assistance Benefits Depress Residential Integration?}

As summarized in the introduction, the explanations of ethnic residential segregation can be categorized into three broad broad theoretical perspectives. The socioeconomic view argues that ethnic differentials in resources explain the individual's residential choice such that higher levels of income, 
education, and wealth improve access to the more advantaged neighborhoods (Borjas 1998; Crowder and Krysan 2016; Sager 2012). The start help reform clearly induced quasi-random variation on this mechanism by decreasing the income base among those refugees who obtained residency after the start help cutoff, whereas refugees who obtained residency before remained unaffected. The reform thus cut assistance benefits by up to 50 percent depending on household composition (see Table A.1 in the supplementary material (SM) for information about the different assistance levels). This marked reduction de facto placed new refugees at a subsistence minimum in Denmark. Consequently, it can be expected to deprive start help refugees from location options that are economically available to regular assistance refugees. On the assumption that housing is less expensive in areas of high ethnic concentration, this deprivation mechanism makes for the first theoretical prediction that start help refugees settle in more ethnically concentrated neighborhoods compared to refugees who were eligible for regular assistance. An addition implication of this assumption makes for the second theoretical prediction that start help refugees is settled in areas of relative deprivation-e.g., areas of higher welfare dependency—compared to regular assistance refugees.

The above discussions also raise the important question of potential effect heterogeneity. In particular, the deprivation mechanism might very well be contingent on refugees' education level. Thus, low educated refugees face larger resource constraints and more marginalization, which makes it difficult to get foothold on the labor market. To the contrary, high educated refugees face fewer resource constraints and less marginalization, which make them better capable of getting a foothold on the labor market that could give them socioeconomic success and the possibility of relocating into neigborhoods with better better housing and amenities that would also imply greater coresidence and social interaction with natives. This makes for the third theoretical prediction that the increase in residential segregation is concentrated among the low educated. 
While the start help reform taps into the socioeconomic mechanism by lowering refugees' income, I argue that it did not affect the two alternative explanations. First, the individual preference perspective assert that out-group avoidance or in-group affinity lead individuals' to choose neighborhoods with high concentrations of their own group (Charles 2006; Clark 2009; Crowder and Krysan 2016). This means that ethnic segregation arises from ethnic differences in social preferences for neighborhood composition (Clark 1991, Schelling 1971, 1969). In this logic, the start help reductions might drive ethnic concentration if the reform is perceived as a discriminatory signal of disrespect and misrecognition. Following Schelling's $(1971,1969)$ model of segregation, this would lead to a process of self-segregation. Second, the ethnic stratification perspective contends that discriminatory practices by local (Musterd, Ostendrof, and Breebaart 1998) and national institutions (Giffinger 1998), mortgage providers (Galster 1999; Aalbers 2005), landlords (Phillips 1998), and estate agents (Phillips and Karn 1992; Yinger 1999) create an ethnically segmented housing market. Even for refugees in a good economic position, this makes it difficult to acquire a dwelling in neighborhoods of high socioeconomic status (Bolt, Van Kempen, and Van Ham 2008). Both these mechanisms build on a signaling effect of the reform that can be expected to affect refugees equally across the start help cutoff. This means that a potential difference in location choice between start help and regular assistance refugees should not reflect a change in individual preferences nor a shift in discriminatory practices found in the housing market.

\section{Is Residential Integration an Important Indicator for Refugee Integration?}

There is not one agreed upon measure of refugee integration that is applied consistently in the literature. Instead, integration is a multifaceted concept and different studies have used different measures 
to capture the various dimensions of integration. Building on Kymlicka's (2012) definition of integration $^{1}$, Harder et al. (2018), for example, discuss six dimensions of integration including, social, economic, political, psychological, linguistic, and navigational integration. Moreover, they show that these dimensions tend to be highly correlated, such that a high level on one dimension is associated with a high level on another dimension. In this study, I focus on residential integration. Residential integration can be justified as an important measure of refugees' integration success both theoretically and empirically.

Theoretically, residential integration may firstly be viewed as an important marker of social integration into the host society. Residential integration thus affects refugees' likelihood of forming social ties and interactions with natives in the host country, which is viewed as important concepts underlying the definition of social integration (Harder et al. 2018). Location matter because neighbourhoods provide an important context for social interactions and shape their residents' opportunities and life chances (Sampson et al. 2002). For example, mixed-race neighbourhoods provide the potential for crosscultural interactions that can promote integration by breaking down stereotypes and prejudice (Fong and Wilkes 2003) and thereby fostering contact, which could lead to social ties and acceptance across different groups (Wu, Schimmele, and Hou 2012). Moreover, ethnic concentration may secondly itself depress refugees' integration into the host society. Thus, ethnic concentration is commonly recognized as an impediment on refugees' integration process because it is perceived to slow down their acquisition of country-specific human capital, including language skills and knowledge about the host country (Damm and Rosholm 2010).

Empirically, Harder et al. (2019) have shown the dimensions of integration to be highly correlated. This means that ethnic concentration can very well be expected to go hand-in-hand with

\footnotetext{
${ }^{1}$ Who sees success as the "full opportunity for immigrants and their offspring to achiece a wide range of social, economic, and political mobility in their host society." Integration is thus means that all barriers to full participation in the society have been removed.
} 
integration failure in other dimensions. This is corroborated by research that links ethnic concentration with exposure to crime (Case and Katz 1991; Peterson and Krivo 2010) and poverty (Logan 2011). Moreover, researchers have shown concentration to be negatively correlated with earnings (Thomas and Moye 2015), wealth (Shapiro, Meschede, and Osoro 2013), employment (Cutler and Glaeser 1997; Van der Klaauw and Van Ours 2003), educational achievement (Cutler and Glaeser 1997; Burdick-Will et al. 2011), and health (Kershaw and Albrecht 2015; White and Borrell 2011; Yang and Matthews 2015).

Altogether, this has fostered a clear consensus among policy-makers that residential segregation of ethnic minorities from the native majority population is unwanted and problematic. The Danish parliament, for example, recently adopted the statement that the concentration of immigrants and descendants from non-Western countries in certain residential areas is worrying (see the SM for the full statement) and subsequently adopted new legislation designed to dilute the concentration of non-Western immigrants in certain high-concentration neighborhoods. Moreover, cities that receive large shares of the refugee inflow often consider this a financial and social burden (Damm and Rosholm 2010). Consequently, many countries - e.g., Germany, United Kingdom, the Netherlands, Switzerland, United States, Norway, Sweden, and Denmark — have instituted policies that direct new refugees away from immigrant-dense areas in the large cities and reduce the fiscal and social strain on individual localities. Residential integration is thus considered a key goal for the design of policy.

\section{Research Design}

\section{The Start Help Reform}

To avoid raising questions of ethnic discrimination, the start help rules applied to all citizens who obtained residency after July 12002 and had lived abroad for more than one of the last eight years. 
To the contrary, refugees who obtained residency before July 12002 would generally remain eligible for regular assistance (Huynh, Schultz-Nielsen, and Tranæs 2007; Rosholm and Vejlin 2010). Here, residency refers to the date that the municipal council takes over the integration responsibility for the refugee, cf. the Integration Act $\S 4 .^{2}$ As an exception to the general rules, the reform capped the benefits of couples if one spouse obtained residency before the threshold of July 1 and the other after. In particular, total household benefits were capped such that it would not exceed the amount that two refugees on start help would receive. This means that a refugee who obtained residency before the reform, but whose spouse obtained after, is de facto under the start help rules. Depending on family composition, start help recipients experienced welfare reductions up to 50 percent compared to regular assistance recipients (Andersen 2007). Table A.1 in the supplementary material (SM) shows the assistance level of different family types.

The motivation of these massive cuts was to promote labor market integration of refugees and thereby pave the way for integration more broadly (Danish Prime Minister's Office 2002). Importantly, only refugees and their reunified family members were affected systematically by the reform. Other types of immigrants, such as labor migrants, who wish to obtain residency are supposed to provide for themselves or be provided for by their spouses (Huynh, Schultz-Nielsen, and Tranæs 2007; Rosholm and Vejlin 2010). In the results section below, I therefore focus only on refugees and their families.

The start help reform was part of a larger reform package that also tightened the reunification law (reunification would now only be possible if both spouse were at least 24 years old), removed the possibility of seeking asylum at Danish embassies abroad, and replaced the concept "de

\footnotetext{
${ }^{2}$ According to the Integration Act $\S 4$, the municipal council takes over the integration responsibility for the refugee refugee after the end of the first whole month of obtaining residence permit. If the refugee, for example, received her permit March 8, the responsibility passes to the municipal council May 1. For reunified refugees, quota refugees, and refugees who applied for asylum at Danish embassies, the municipal council takes over the integration responsibility when the refugee is registered as having arrived in the municipality or if the application is submitted in Denmark from the announcement of residence permit.
} 
facto refugee" status with "protection status". These restrictions made it significantly more difficult to immigrate to Denmark both through family reunification and as a refugee (Huynh, Schultz-Nielsen, and Tranæs 2007). With typical observational data, I would risk attributing the effects of these policy changes to the effect of the start help reform. However, the start help reform referred to the date of residency whereas the other policies referred to the asylum application date (Huynh, Schultz-Nielsen, and Tranæs 2007). This means that refugees were affected equally across the threshold of July 1 by these additional policy changes, whereas only refugees who obtained residency after the threshold were affected by the start help changes. Consequently, it allows me to separate the causal effect of start help from immigration restrictions.

Another potential source of bias is the Danish dispersal policy that affects the initial placement of refugees. This policy disperses all refugees across municipalities according to a prespecified distribution $\mathrm{key}^{3}$. Moreover, placement in the assigned municipality is mandatory for the first three years. Thus, reception of social assistance benefits is conditional on residing in the assigned municipality for a three-year period. Importantly, however, this policy was adopted in 1999 and was stable across the cutoff of July 12002 . This means that it does not affect the causal interpretation of the effects under investigation in this study. Instead, one could expect the dispersal policy to limit the short-term impact of the start help reform given that it de facto creates a geographical lock-in in the short-term.

\section{Selection Biases and Causal Identification}

I leverage the fact that the Danish start help reform induced a discontinuity in social assistance eligibility of refugees. In particular, I exploit this discontinuity in a RD design that provides unbiased estimates under the assumption that the potential residential outcomes are continuous at the start help

\footnotetext{
${ }^{3}$ This key is computed as the municipality's share of the total population subtracted the difference between the municipality's share of the total number of immigrants and refugees and the municipality's share of the total population.
} 
cutoff of July 1 (Hanh, Todd, and Van der Klaauw 2001). This identifying assumption fails if refugees sort around the threshold, which would only happen if manipulation with the date of residency occurs. I argue that the setting provides a local experiment that - in the same way as a randomized experiment - enables me to isolate the causal effect of reducing assistance benefits and overcome the selection bias that I discuss below.

Manipulation could arise in two distinct stages. In the first stage, refugees decide whether to apply for asylum in Denmark or not. If refugees were able to anticipate the reform, there is a risk that refugees sort in a manner that create selection bias in the effect estimates. However, the short parliamentary processing time of the start help reform combined with the mean asylum application processing time strongly suggest that first-stage self-selection is not a problem. Thus, the start help reform was proposed for the first time on March 12002 and adopted as of July 1. At the same time, there was a mean asylum application processing time of about 15 months (Hvidtfeld et al. 2017). This implies that refugees did not have sufficient information to anticipate the reform when deciding in which country to apply for asylum.

In the second stage, applications are reviewed and it is decided who obtains a permit and who does not. Decision-makers that review applications typically decide on a much more informed basis about applicants than what the researcher observes. If decision-makers prefer specific refugees, it could create bias in the estimated effects. However, two factors alleviate the concern over second stage selection bias. First, that decision-makers potentially prefer certain types of refugees to others is not enough to create bias in the estimates. They would also have to process their applications faster compared to other applicants. This seems inconceivable. It would create a bias given that preferred applications would be more likely to obtain residency on the beneficial side of the start help cutoff compared to unpreferred applicants. Second, the Danish Immigration Service - that decides 
whether there is a basis for granting asylum — bases its decision entirely on the legal criteria of the applicant's need for protection.

Taken together, the above arguments strongly suggest that refugees were not able to manipulate the start help cutoff and in this way corroborate the validity of the identifying assumption of continuous potential outcomes across the cutoff. However, it is important to recognize that the validity of the continuity assumption is ultimately an empirical question. I return to this question below.

\section{Data, Sample Selection, Covariates, and Outcome}

My data are based on the Danish national registers. The registers allow for the construction of a dataset that links information based on a unique personal identifier. Based on this identifier, I combine information on the exact date of residency and information on the individual refugee's residential surroundings (by January 1 2015). I select all refugees-including those who are family reunified with refugees — who obtained their residency within a bandwidth of \pm 6 months from the threshold, but in the SM, I also show that results are robust across various widths of the estimation window (see Figure A.2 in the SM). I focus only on refugees and their families because refugees and their reunified family members are the only immigrant group that is systematically affected by the reform (see the description of the start help above). I include only refugees between 18 and 55 years old at the time of residency as they were in the working age and eligible for social assistance. Moreover, I exclude refugees who re-migrate at some point during the period of analysis.

I merge characteristics of the individual to her family based on unique spouse and family identifiers. The covariates capture background characteristics of the refugees as reported in the national registers. They include sex, age, education, grouped origin, first region of residency, whether 
the refugee is married or not, and whether the refugee has children or not. The SM provides descriptive statistics for all variables (see Table A.2).

The start help indicator (the treatment indicator) is coded in accordance with the eligibility criteria (see the description of the start help reform above). In general, this means that the treatment is coded 1 for refugees who obtained residency after July 1 and 0 for refugees who obtained residency before July 1 . However, spouses that obtained residency on each side of July 1 are both de facto only eligible for start help and are therefore both assigned 1 on the treatment indicator. To ensure consistency between date of residency and eligibility status, these spouses are assigned the date of residency of the last arriving spouse.

This treatment indicator allows me to estimate the causal effect of being eligble for reduced compared to regular assistance benefits on location choice. This is akin to an intention-totreat (ITT) estimate of actually receiving reduced benefits because refugees are only affected directly by the reform if they remain unemployed. To estimate the average treatment effect (ATE) of receiving reduced benefits would require the identification of "compliers", i.e., refugees who remain uemployed. The estimation of this ATE is essentially nonsensical or practically impossible because the definition of compliers is inherently arbitrary given that individuals move in and out of employment all the time. Two properties of the ITT effect are, however, important to note. First, one might argue that the ITT is in fact the more relevant quantity to estimate from a policy perspective. Thus, whereas policy-makers can directly adjust social assistance levels they can only indirectly influence employment. Second, refugees typically do not enter the job market immediately. Instead, most refugees remain affected by the reform, at least during their first years in Denmark (the employment rate is, for example, about 11 percent within the first year of residency).

The outcome - residential integration — is measured as the concentration of non-Western immigrants in the individual's residential surroundings. In particular, I compute the residential 
integration measure at the parish level, which is the smallest pre-defined administrative and geographically delimited unit in Denmark (the average parish population size is 2,603). I focus on nonWestern immigrants because these differ the most from the native population-ethnically as well as culturally - and they form the group over which most political contestation has occurred (Dinesen and Sønderskov 2015) ${ }^{4}$. The national registers hold information about addresses and the country of origin for everyone residing in Denmark, which I use to construct the concentration measure. In particular, I have information on refugees' addresses as of January 1 every year from 2003 through 2015. I group the outcome into three intervals - including the short-, medium-, and long-term - and take the average over the interval years. I define short-term residential integration as the years 2003-2005. The justification for this delineation is the Danish dispersion policy according to which refugees' reception of social assistance benefits is conditional on residing in their assigned municipality for their first three years of residency. I split the remaining 10 years into two equal-sized 5-year intervals. That is, I define the medium-term as effects in the years 2006-2010 and the long-term as years 20112015.

\section{Results}

Below, I estimate the effect of start help on residential integration by regressing the residential integration outcome on the treatment indicator, the residency variable, and the interaction between the two. All effect estimations in the results section focus on the sample of refugees who obtained their residency within a bandwidth of \pm 6 months of the threshold and apply a triangular kernel to focus estimations on refugees' at threshold. To probe the robustness of my results, I show that the results are relatively insensitive to varying the width of the estimation window (see Figure A.3 in the SM).

\footnotetext{
${ }^{4}$ I compute the measure as the share of people in the individual's surroundings who do not originate from the EU-15 countries, Iceland, Norway, Andorra, Liechtenstein, Monaco, San Marino, Switzerland, The Vatican State, Canada, USA, Australia, and New Zealand.
} 
Moreover, the findings are essentially similar when applying a local quadratic specification instead of the local linear (see Table A.7 in the SM). Finally, as I argue below, all identification checks indicate that the RD design is able to isolate this causal effect at the cutoff.

\section{Empirical Assessment of the Continuity Assumption}

Figure 1 illustrates two important indirect tests that check the identification of the RD design. In particular, the left panel of Figure 1 leverages the logic of a local experiment across the threshold. In this logic, one should expect covariates to be balanced at the threshold. I use this intuition in a series of placebo outcome tests, where I substitute in each covariate as a placebo outcome in the RD design to estimate placebo effects. From these analyses, I plot the respective p-values to to show any imbalances across the threshold (the dashed vertical line indicates a p-value of 0.05). (Table A.3 in the SM reports the supporting regression table). The panel shows imbalance in one covariate. In particular, there are fewer females above the threshold. This imbalance reflects that men typically arrive first and are reunified with their spouses later. Given the treatment assignment, where both spouses would only be eligible for start help if one obtained residency above the threshold, this means that men are disproportionately "moved" across the threshold ${ }^{5}$. To be sure, in the results section below, I provide estimates both with and without covariates to control away any potential confounding from observables. Taken together, however, the imbalances are within what one would expect to observe at random. The p-values from the placebo outcome tests thus approximate the uniform distribution as expected given local randomization at the threshold.

[Figure 1 about here]

\footnotetext{
${ }^{5}$ The imbalance disappears if one uses their own date of residency (disregarding family reunifications) as the running variable.
} 
The right panel of Figure 1 illustrates another important implication of the continuity assumption: The density of refugees should be smooth across the threshold. That is, there should be no sorting. If refugees had precise control over their date of residency and the ability to sort, one would logically expect to observe an unusually large (small) density of refugees who obtained residency just before (after) July 1. The right panel shows McCrary's (2008) test for sorting. I compute the density of the residency variable (the difference in days between residency and the threshold) within a window of \pm 6 months around the threshold. The panel shows that there was no sign of sorting. Instead, the density is smooth across the threshold. Moreover, Figure A.1 in the SM demonstrates that there are no discontinuities at placebo cutoffs above and below the true threshold. These tests further bolster the design-based identification and corroborate that the true effect estimate (see below) is indeed an effect of the start help reform rather than an artefact of a jumpy relationship between the forcing variable and the outcome.

Altogether, the substantive justification provided above and the empirical results from the identification tests strongly support that the start help reform provides an ideal design for identifying the causal impact of reducing refugees' benefits on their residential integration.

\section{Overall Effect of Lower Benefits on Residential Integration}

Figure 2 presents the main findings for the effect of lower benefits on refugees' residential integration (Table A.4 in the SM reports the supporting regression table). The marginal differences, shown in the figure, display the estimates from regressing the residential outcome on the treatment indicator, the residency variable, and the interaction between the two. The black filled circles show the estimates from models without covariates and the grey filled triangles show the estimates from models with covariates. The inclusion of covariates checks the design-based identification. If refugees who obtain 
residency just before and after the threshold are similar in all confounding respects_-as local randomization stipulates - then including or excluding covariates should not substantially alter the effect estimate. Consistent with the placebo outcome tests above, the effect estimates are relatively stable across the models with and without covariates.

The figure shows a clear empirical pattern that is consistent with the theoretical expectations. In the short-term, there is no effect of lower benefits $\left(\alpha_{\text {without covariates }}=0.64, \mathrm{P}<0.32 ; \alpha_{\text {with }}\right.$ covariates $=0.15, P<0.80$ ). To the contrary, one sees a sharp increase of the effect estimates in the medium-term $\left(\alpha_{\text {without covariates }}=3.01, \mathrm{P}<0.027 ; \alpha_{\text {with covariates }}=2.61, P<0.018\right)$. Taken together, these results show that the Danish dispersion rules effectively limit the effect of the benefit reduction on residential integration in the short-term. However, once refugees' can freely move-without facing economic sanctions - the effect materializes. Thus, one one observes an increase in the share of nonwestern immigrants by about 3 percentage points in the medium-term. This effect increases further in the long-term $\left(\alpha_{\text {without covariates }}=3.95, \mathrm{P}<0.011 ; \alpha_{\text {with covariates }}=3.56, P<0.013\right)$. This means that start help refugees live in neighborhoods where the concentration of non-western immigrants is about 4 percentage points larger compared to regular assistance refugees. It corresponds to an increase of about 28 percent compared to the counterfactual at the threshold. (Figure A.2 displays the results of the RD design graphically; consistent with the marginal differences, these analyses demonstrates that there is no jumps in the ethnic concentration in the short-term whereas there are clear jumps in the concentration in the medium- and long-term).

[Figure 2 about here]

The above results are striking as I compare refugees who are identical in terms of their background characteristics but separated by only a few days with regard to residency. Moreover, this 
sizable effect is robust across various robustness checks. Thus, Figure A.3 in the SM shows that the effect estimates are remarkably stable across different widths of the estimation window. Moreover, Table A.7 in the SM demonstrates that the estimates are robust to using a local quadratic specification rather than the local linear. Taken together, these results are consistent with the first theoretical prediction that lowering the benefits of refugees drive ethnic residential concentration.

\section{Testing the Mechanism: Effect on Neighborhood Welfare Dependency}

What mechanism might drive this overall effect? As discussed in theory section, the reform can be expected to send the same signal to refugees across the start help threshold. Theoretically, this means that one can rule out mechanisms — such as individual preferences or discrimination — that build on such signaling effects. To the contrary, the reform clearly induce differentials in refugees' resources across the threshold. Although, the results are consistent with the deprivation mechanism, it is of course an empirical question whether this mechanism is the predominant driver of the overall effects rather than some alternative mechanism. An assumption that underpins the deprivation mechanism is that housing is less expensive in residential areas where the concentration of non-western immigrants is high. This assumption yields the testable implication that start help refugees live in neighborhoods where the welfare dependency rate is higher compared to regular assistance refugees.

To test this proposition, I replicate the above models while using the neighborhood share of unemployed as an alternative outcome. Figure 3 illustrates the results of these analyses (Table A.5 in the SM reports the supporting regression table). The figure clearly shows that the RD effects on neighborhood welfare dependency closely mirrors the above effects on ethnic concentration. Thus, one observes no effect in the short-term $\left(\alpha_{\text {without covariates }}=0.54, \mathrm{P}<0.540 ; \alpha_{\text {with covariates }}=0.95, P<\right.$ $0.257)$, whereas there is a clear effect in the medium-term $\left(\alpha_{\text {without covariates }}=1.99, \mathrm{P}<0.030 ; \alpha_{\text {with }}\right.$ 
covariates $=2.44, P<0.005)$ that increases slightly in the long-term $\left(\alpha_{\text {without covariates }}=2.12, \mathrm{P}<0.038\right.$;

$\left.\alpha_{\text {with covariates }}=2.56, P<0.013\right)$.

[Figure 3 about here]

Overall, these results strongly corroborate the assumption that housing prices and the concentration of non-western immigrants go hand-in-hand. This means that the findings are consistent with the second theoretical prediction that start help refugees settle in areas of relative deprivation compared to regular assistance refugees.

\section{Effect Heterogeneity}

The above results also raises the important question of effect heterogeneity. In the theory section, I discussed how the deprivation mechanism might very well be contingent on refugees' education level such that the start help effect is concentrated among the low educated who are less resourceful, face more marginalization, and therefore less likely to get a foothold on the labor market. I test this proposition in Figure 4, where I estimate the RD effects on ethnic concentration while splitting the sample according to education level. In particular, I split education at arrival into low (black circles), medium (grey triangles), and high (grey squares) educated. ${ }^{6}$ Consistent with the deprivation mechanism, the figure quite clearly demonstrates that effects are concentrated among the low educated.

[Figure 4 about here]

\footnotetext{
${ }^{6}$ I define low education as less than or equal to 120 months, which corresponds to $10^{\text {th }}$ grade in the Danish primary school (to this group I also add refugees with an unknown education level), medium education as more than 120 months but less than 180 months that corresponds to a bachelor's degree, and high education as 180 months or more.
} 
Thus, the low educated experience statistically significant and large effects in the medium- and long-term $\left(\alpha_{\text {short-term }}=1.30, P<0.149 ; \alpha_{\text {medium-term }}=4.72, P<0.041 ; \alpha_{\text {long-term }}=6.90, P<\right.$ 0.013). Compared to the counterfactual refugee at the threshold - who is eligible for regular assistance - this corresponds to increases of about 50 percent in the concentration of non-western immigrants in their neighborhoods. To the contrary, the effects between the medium and high educated is all statistically insignificant and relatively small. (Table A.6 in the SM report the supporting regression table and provides results that show that the effect estimates are robust to the inclusion of covariates). Taken together these results fit the theoretical prediction - that derived from the deprivation mechanism - that the start help effect is driven by the low educated who face the largest resource constraints and most marginalization. Consequently, they further corroborate that the overall effect is driven by deprivation, where start help refugees live on a subsistence minimum that significantly limit their location choice.

\section{CONCLUSION}

In this article, I provide new and credible causal evidence for the effects of reducing refugees' benefits on their residential integration. The findings have important implications for the design of policy as well as theory. First, the findings show that benefit reductions drive ethnic residential concentration. This effect is quite substantial, especially in the long-term. It thus raises long-term ethnic concentration by about 28 percent. It is a quite remarkable effect given that it represents two refugees who are separated by only a few days with regard to residency, but settle in very different residential surroundings in the long-term. Moreover, this overall effect most likely runs through a deprivation mechanism: Start help refugees live on a subsistence minimum that significantly limit their location choice. Overall, this contrasts the theoretical view that lower benefits incentivizes refugees to integrate into the host society more broadly. Instead, it suggests that lowering refugees' benefits - to or below the 
subsistence minimum - mainly creates further barriers for the integration of the majority of new refugees rather than positively contributing to their integration.

Second, the results suggest that the increase in residential segregation is concentrated among the low educated. Thus, in the long-term, low educated start help refugees lived in neighborhoods where the ethnic concentration was about 50 percent higher compared to regular assistance refugees. From a policy standpoint, these findings are concerning because they show that low benefits marginalize those who have little chances of integrating into the host society further and push them to the edges of the society. In line with recent work (e.g. Marbach et al 2018, Hainmueller et al 2016), the findings thus point to the existence of an influential early integration window that affect refugees' subsequent integration trajectory disproportionately.

Third, the results contributes to the literature on residential segregation by providing new and reliable causal evidence for the socioeconomic mechanism as a driver of residential segregation. Thus, a key problem for most studies on the causes of residential segregation is the issue of omitted variable bias. I solve this issue by leveraging quasi-experimental variation in assistance benefits and show that the results are robust over various tests that check the design-based identification. While the results get better causal leverage on the socioeconomic mechanism than most existing studies, it is important to note that they do no not reject prior research.

Fourth, the findings also contribute to the literature that focus on the effects of benefit reductions on integration more generally. This literature has mainly focused on short-term economic effects of reducing refugees' benefits (e.g. Rosholm and Vejlin 2010; Huynh, Schultz-Nielsen, and Tranæs 2007). From a policy standpoint, this is concerning because policy-makers may not be fully aware of the consequences of their decisions when designing the policies. These results nuance this picture by providing reliable causal evidence for the negative long-term effect of benefit reductions on residential integration. 
While the research design provides high internal validity, the design is more limited in terms of the external validity of the results. The generalizability beyond Denmark is thus an open question. One way of assessing the generalizability of the findings is to compare the strictness of Danish integration policies to the regimes in other Western countries. One guide for making this assessment is the migrant policy integration index (MIPEX). On the MIPEX, Danish policies are about as restrictive as the sample median (see Figure A.4 of the SM). This may suggest that the effect estimates might be representative more broadly. Note, however, that external validity is best studied by replicating the results in studies with high internal validity in other countries and other time periods. 


\section{References}

Aalbers, Manuel B. 2005. "Who's afraid of red, yellow and green?: Redlining in Rotterdam." Geoforum 36 (5):562-580.

Andersen, Jørgen Goul. 2007. "Restricting access to social protection for immigrants in the Danish welfare state." Benefits 15 (3):257-269.

Bolt, G., A.S. Özüekren, and D. Phillips. 2010. Linking integration and residential segregation. Journal of Ethnic and Migration Studies 36(2):169-186.

Borjas, George J. 1998. "To ghetto or not to ghetto: Ethnicity and residential segregation." Journal of Urban Economics 44 (2):228-253.

Burdick-Will, Julia, Jens Ludwig, Stephen W Raudenbush, Robert J Sampson, Lisa Sanbonmatsu, and Patrick Sharkey. 2011. "Converging evidence for neighborhood effects on children's test scores: An experimental, quasi-experimental, and observational comparison." Whither opportunity:255-276.

Case, Anne C, and Lawrence F Katz. 1991. The company you keep: The effects of family and neighborhood on disadvantaged youths. National Bureau of Economic Research.

Charles, Camille Zubrinsky. 2003. "The dynamics of racial residential segregation." Annual review of sociology 29 (1):167-207.

Charles, Camille Zubrinsky. 2006. Won't you be my neighbor: Race, class, and residence in Los Angeles: Russell Sage Foundation.

Clark, William AV. 1991. "Residential preferences and neighborhood racial segregation: A test of the Schelling segregation model." Demography 28 (1):1-19.

Clark, William AV. 2009. "Changing residential preferences across income, education, and age: Findings from the multi-city study of urban inequality." Urban Affairs Review 44 (3):334355. 
Crowder, Kyle, and Maria Krysan. 2016. "Moving Beyond the Big Three: A Call for New Approaches to Studying Racial Residential Segregation." City \& Community 15 (1):18-22.

Cutler, David M, and Edward L Glaeser. 1997. "Are ghettos good or bad?" The Quarterly Journal of Economics 112 (3):827-872.

Damm, A. P. (2009). Ethnic enclaves and immigrant labor market outcomes: Quasi-experimental evidence. Journal of Labor Economics, 27(2), 281-314.

Damm, A. P., \& Rosholm, M. (2010). Employment effects of spatial dispersal of refugees. Review of Economics of the Household, 8(1), 105-146.

Danish Prime Minister's Office. 2002. "På Vej Mod En Ny Integrationspolitik." Vol. Copenhagen: Danish Prime Minister's Office.

Dinesen, Peter Thisted, and Kim Mannemar Sønderskov. 2015. "Ethnic diversity and social trust: Evidence from the micro-context." American Sociological Review 80 (3):550-573.

Fong, E. and R. Wilkes. 2003. Racial and ethnic residential patterns in Canada. Sociological Forum 18(4):577-602.

Galster, George. 1999. "The evolving challenges of fair housing since 1968: open housing, integration, and the reduction of ghettoization." Cityscape:123-138.

Giffinger, Rudolf. 1998. "Segregation in Vienna: impacts of market barriers and rent regulations." Urban Studies 35 (10):1791-1812.

Hahn, Jinyong, Petra Todd and Wilbert Van der Klaauw. 2001. "Identification and Estimation of Treatment Effects with a Regression-Discontinuity Design." Econometrica 69(1):201-09.

Hainmueller, Jens, Dominik Hangartner and Giuseppe Pietrantuono. 2015. "Naturalization Fosters the Long-Term Political Integration of Immigrants." Proceedings of the National Academy of Sciences 112(41):12651-56. 
Hainmueller, Jens, Dominik Hangartner and Giuseppe Pietrantuono. 2017. "Catalyst or Crown: Does Naturalization Promote the Long-Term Social Integration of Immigrants?". American Political Science Review, 111(2), 256-276.

Hainmueller, Jens, Dominik Hangartner and Duncan Lawrence. 2016. When lives are put on hold: Lengthy asylum processes decrease employment among refugees. Science advances, 2(8), e1600432.

Harder, N., Figueroa, L., Gillum, R. M., Hangartner, D., Laitin, D. D., \& Hainmueller, J. 2018. Multidimensional measure of immigrant integration. Proceedings of the National Academy of Sciences, 115(45), 11483-11488.

Holland, Paul W. 1986. "Statistics and Causal Inference." Journal of the American statistical Association 81(396):945-60.

Huynh, Duy T, Marie Louise Schultz-Nielsen, and Torben Tranæs. 2007. Employment effects of reducing welfare to refugees: Rockwool Foundation.

Hvidtfeldt, Camilla, Marie L. Schultz-Nielsen, Erdal Tekin and Mogens Fosgerau. 2017. “Asylum Process and Employment among Refugees: How Bad is Waiting Time?” Working paper.

Kershaw, Kiarri N, and Sandra S Albrecht. 2015. "Racial/ethnic residential segregation and cardiovascular disease risk." Current cardiovascular risk reports 9 (3):10.

Kymlicka, W. (2012). Multiculturalism: Success, failure, and the future. Migration Policy Institute, Washington DC).

Marbach, Moritz, Jens Hainmueller and Dominik Hangartner. (2018). The long-term impact of employment bans on the economic integration of refugees. Science advances, 4(9), eaap9519.

Murdie, R. and S. Ghosh. 2010. Does spatial concentration always mean a lack of integration? Exploring ethnic concentration and integration in Toronto. Journal of Ethnic and Migration Studies 36(2):293-311. 
Musterd, Sako, Wim Ostendorf, and Matthijs Breebaart. 1998. Multi-ethnic metropolis: patterns and policies. Vol. 43: Springer Science \& Business Media.

Musterd, Sako. 2003. Segregation and integration: A contested relationship. Journal of Ethnic and Migration Studies 29(4):623-641.

Logan, John R. 2011. "Separate and unequal: The neighborhood gap for blacks, Hispanics and Asians in Metropolitan America." Project US2010 Report:1-22.

Peterson, Ruth D, and Lauren J Krivo. 2010. Divergent social worlds: Neighborhood crime and the racial-spatial divide: Russell Sage Foundation.

Phillips, Deborah. 1998. "Black minority ethnic concentration, segregation and dispersal in Britain." Urban Studies 35 (10):1681-1702.

Phillips, Deborah, and Valerie Karn. 1992. "Race and housing in a property owning democracy." Journal of Ethnic and Migration Studies 18 (3):355-369.

Rosholm, Michael, and Rune Vejlin. 2010. "Reducing income transfers to refugee immigrants: Does start-help help you start?" Labour Economics 17 (1):258-275.

Sager, Lutz. 2012. "Residential segregation and socioeconomic neighbourhood sorting: Evidence at the micro-neighbourhood level for migrant groups in Germany." Urban Studies 49 (12):26172632.

Sampson, R.J., J.D. Morenoff, and T. Gannon-Rowley. 2002. Assessing "neighborhood-effects": Social processes and new directions in research. Annual Review of Sociology 28:443-478.

Schelling, Thomas C. 1969. "Models of segregation." The American Economic Review 59 (2):488493.

Schelling, Thomas C. 1971. "Dynamic models of segregation." Journal of mathematical sociology 1 (2):143-186. 
Shapiro, Thomas, Tatjana Meschede, and Sam Osoro. 2013. "The roots of the widening racial wealth gap: Explaining the black-white economic divide." Research and policy brief.

South, Scott J, and Kyle D Crowder. 1998. "Leaving the'hood: Residential mobility between black, white, and integrated neighborhoods." American sociological review:17-26.

Thomas, Melvin, and Richard Moye. 2015. "Race, class, and gender and the impact of racial segregation on black-white income inequality." Sociology of Race and Ethnicity 1 (4):490502.

Van der Klaauw, Bas, and Jan C Van Ours. 2003. "From welfare to work: does the neighborhood matter?" Journal of Public Economics 87 (5):957-985.

White, Kellee, and Luisa N Borrell. 2011. "Racial/ethnic residential segregation: framing the context of health risk and health disparities." Health \& place 17 (2):438-448.

Wu, Z., Schimmele, C. M., \& Hou, F. 2012. Self-perceived integration of immigrants and their children. Canadian Journal of Sociology, 37(4), 381-408.

Yang, Tse-Chuan, and Stephen A Matthews. 2015. "Death by Segregation: Does the Dimension of Racial Segregation Matter?" PloS one 10 (9):e0138489.

Yinger, John. 1999. "Sustaining the fair housing act." Cityscape:93-106. 


\section{Figures and Tables}

Figure 1. The RD Design: Identification Checks

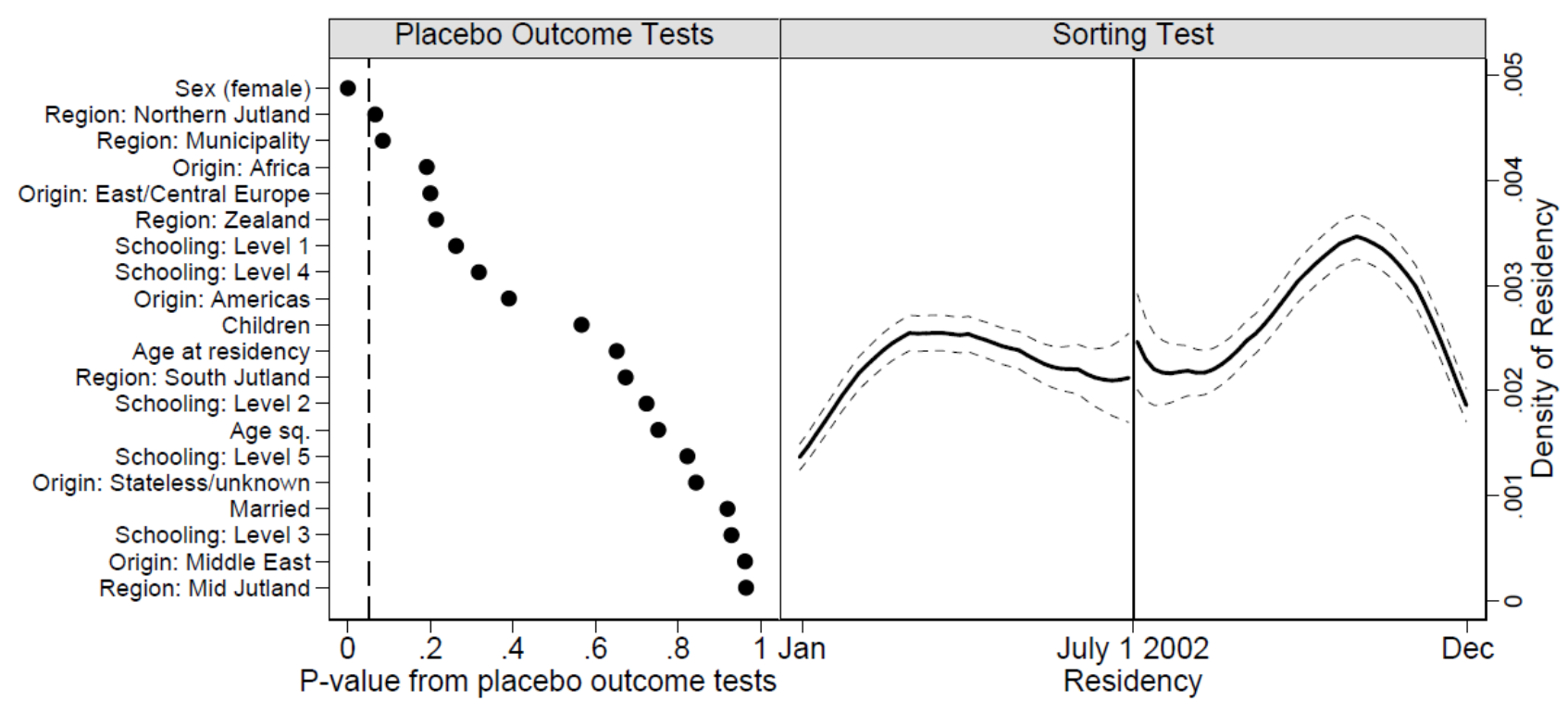

Note: The left panel shows that the age of refugees is well balanced across the threshold. The right panel shows that there is no discontinuity in the density of residency. 
Figure 2. Overall Effect of Lower Benefits on Ethnic Concentration

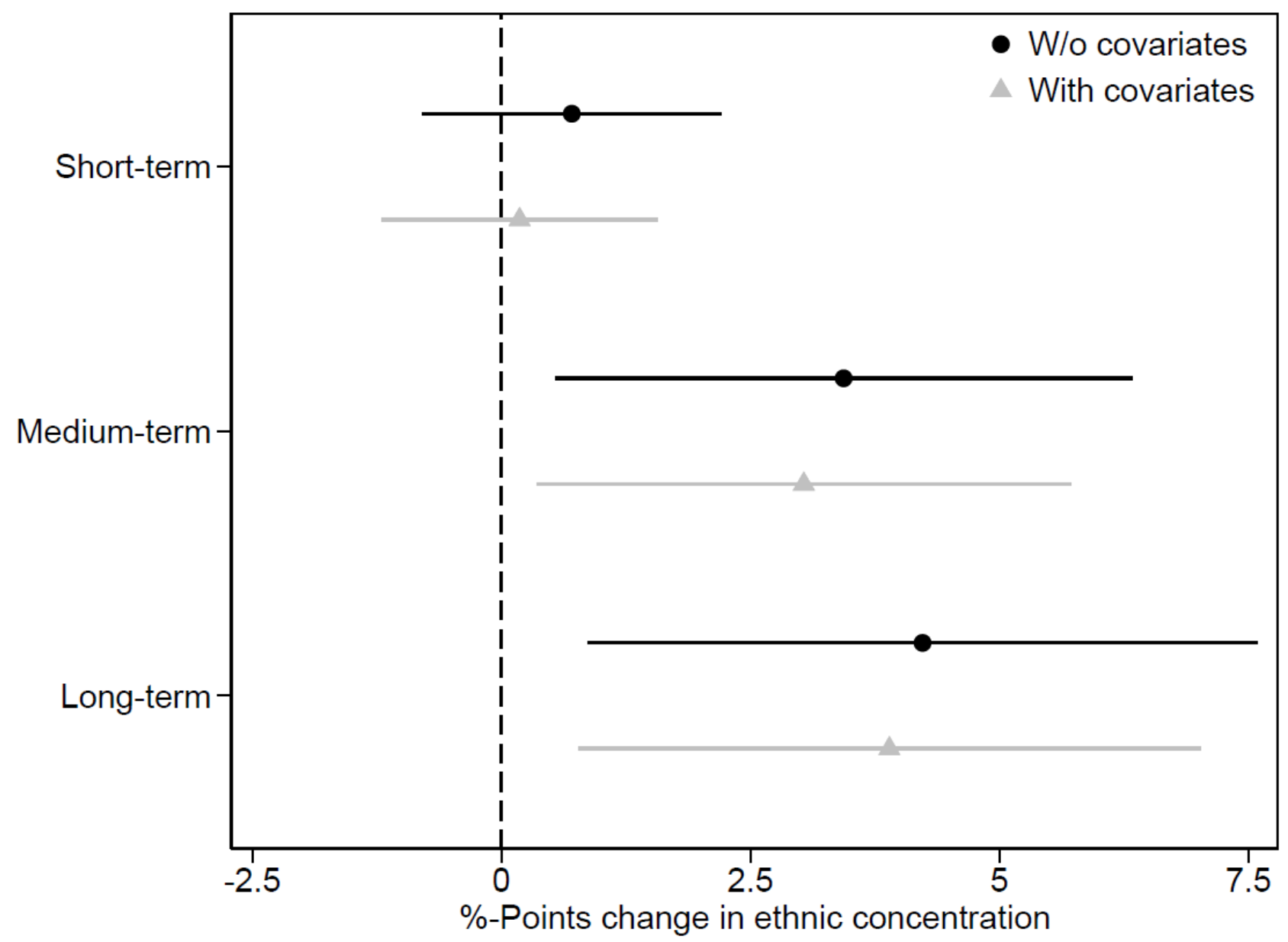

Note: The filled black circles represent the estimates from models without covariates, whereas the grey filled triangles represent the estimates from models with covariates. $95 \%$ confidence intervals. Standard errors are clustered by municipality. Bandwidth \pm 6 months. Kernel $=$ triangular. Covariates: Sex, age, education, married, children, grouped origin, and region of residency. $\mathrm{N}=2,324$. 
Figure 3. RD Effect on Neighborhood Welfare Dependency

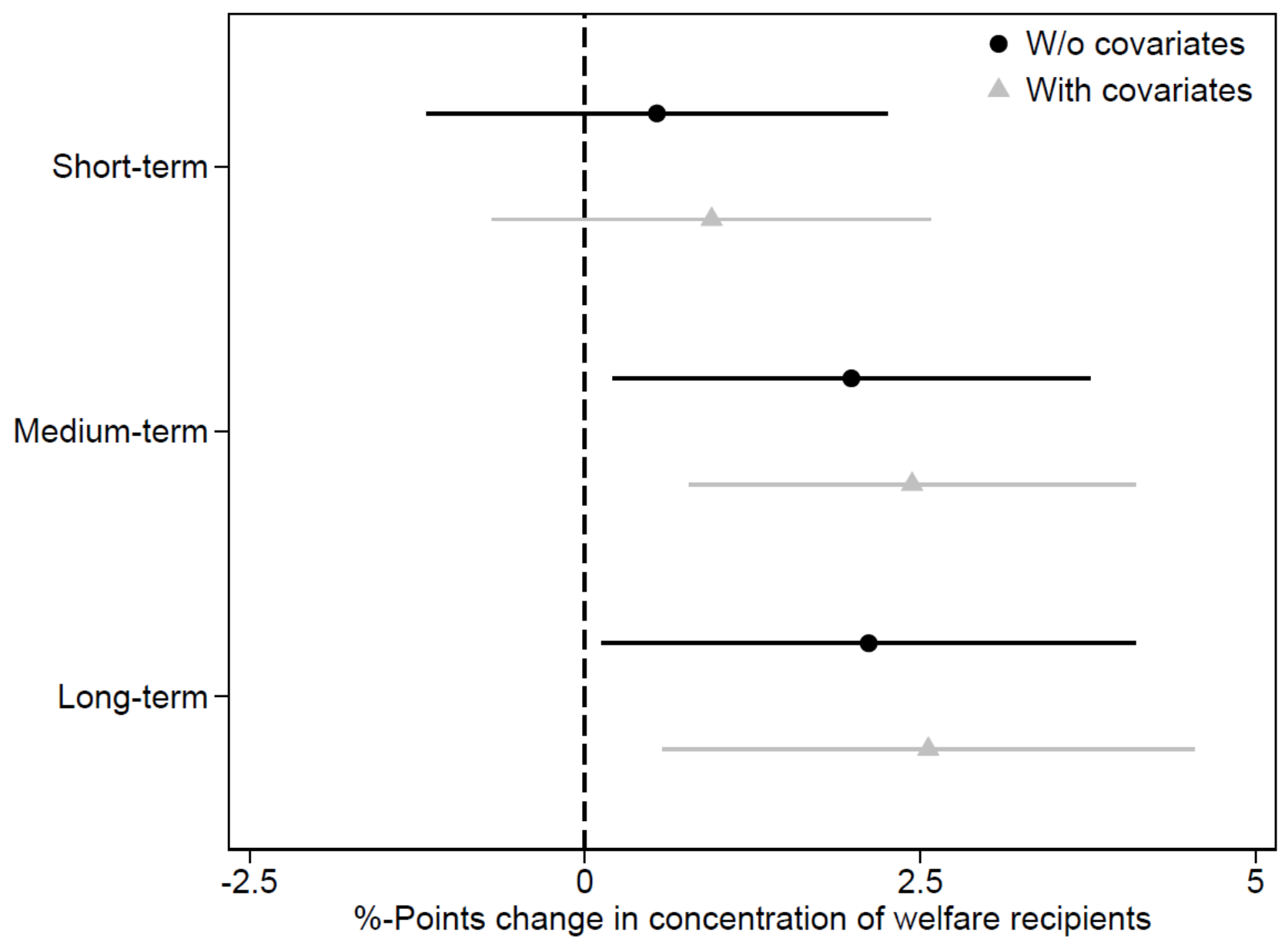

Note: The filled black circles represent the estimates from models without covariates, whereas the grey filled triangles represent the estimates from models with covariates. $95 \%$ confidence intervals. Standard errors are clustered by municipality. Bandwidth \pm 6 months. Kernel $=$ triangular. Covariates: Sex, age, education, married, children, grouped origin, and region of residency. $\mathrm{N}=2,324$. 
Figure 4. Effect Heterogeneity

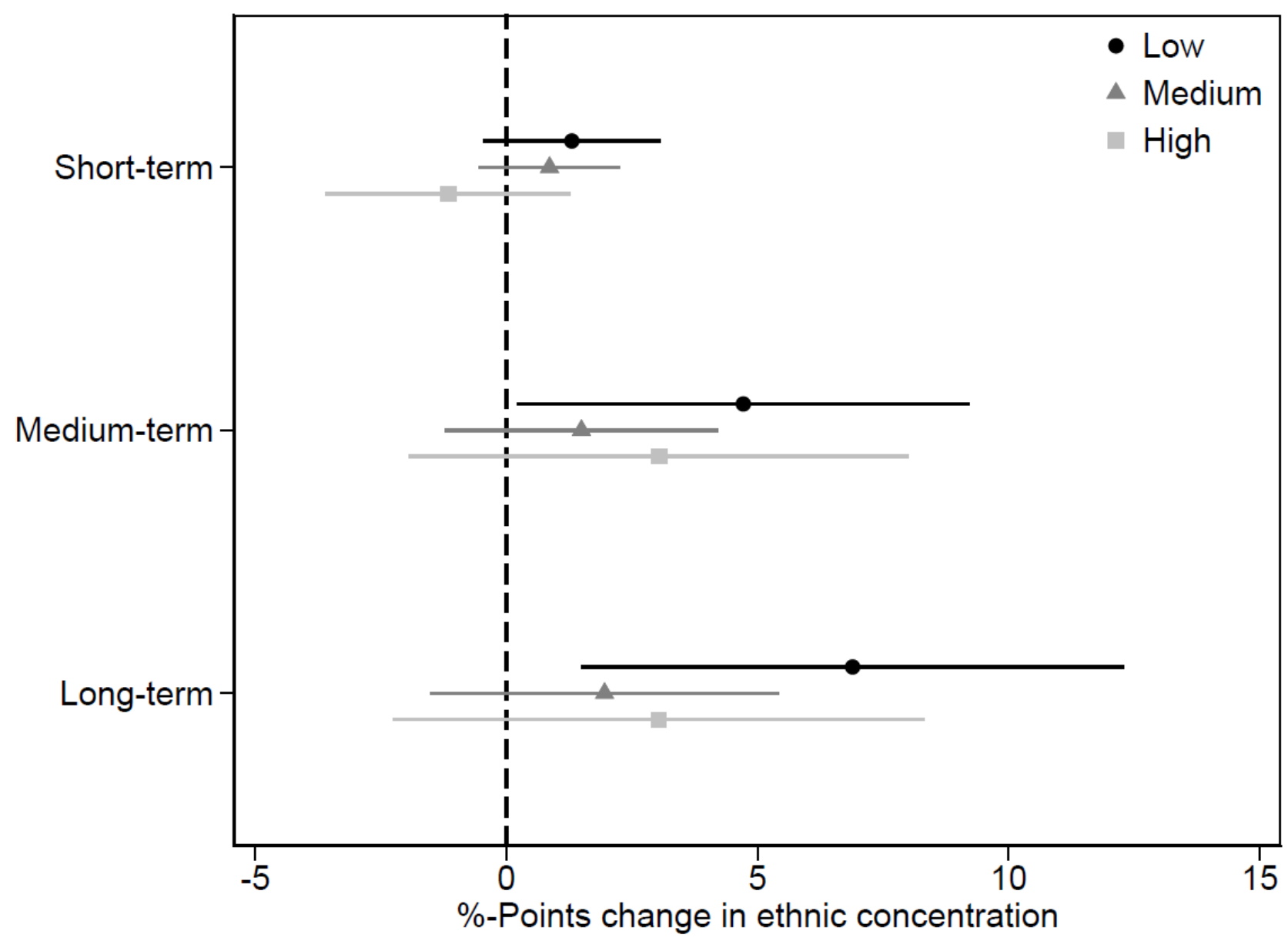

Note: Estimates from models without covariates. The filled black circles represent estimates among the low educated, the filled grey triangles estimates among the medium educated, and the grey filled squares estimates among the high educated. $95 \%$ confidence intervals. Standard errors are clustered by municipality. Bandwidth \pm 6 months. Kernel $=$ triangular. $\mathrm{N}$ (low education $=914$; medium education $=944$; high education $=466$ ). 


\section{Supporting Material Appendices (Not for Publication)}

Statement Adopted in the Danish Parliament

\section{Original Danish statement}

"Folketinget konstaterer med bekymring, at der i dag er områder i Danmark, hvor andelen af indvandrere og efterkommere fra ikkevestlige lande er over 50 pct. Det er Folketingets opfattelse, at danskere ikke bør vare i mindretal i boligområder i Danmark.”

See http://www.ft.dk/samling/20161/vedtagelse/V38/index.htm\#dok

\section{English translation}

"The parliament finds it worrying that there are residential areas in Denmark where the share of immigrants and descendants from non-Western countries exceeds 50 percent. It is the parliament's conviction that Danes should not be a minority in residential areas in Denmark." 
Regular Assistance versus Start Help

Table A.1. Assistance Levels, by Family and Assistance Type

\begin{tabular}{lcccc}
\hline \hline Status & Children & $\begin{array}{c}\text { Regular social assis- } \\
\text { tance }\end{array}$ & $\begin{array}{c}\text { Start } \\
\text { help }\end{array}$ & $\begin{array}{c}\text { Percent reduc- } \\
\text { tion }\end{array}$ \\
\hline Single & 0 & 8,172 & 5,266 & 36 \\
Couples & 0 & 16,344 & 8,732 & 47 \\
Couples & 1 & 21,718 & 9,824 & 55 \\
Couples & $\geq 2$ & 21,718 & 10,916 & 50 \\
\hline \hline
\end{tabular}

Note: Ejrnæs (2003). Gross income in DKK. 
Table A.2. Descriptive Statistics

\begin{tabular}{|c|c|c|c|c|}
\hline Variable & Mean & SD & Min & $\operatorname{Max}$ \\
\hline Treatment & 0.55 & 0.50 & 0.00 & 1.00 \\
\hline Residency & 12.77 & 111.27 & -181.00 & 182.00 \\
\hline Age & 32.61 & 8.00 & 18.00 & 54.92 \\
\hline Female & 0.52 & 0.50 & 0.00 & 1.00 \\
\hline Education (months) & 137.11 & 48.21 & 0.00 & 240.00 \\
\hline Married & 0.74 & 0.42 & 0.00 & 1.00 \\
\hline Children & 0.74 & 0.44 & 0.00 & 1.00 \\
\hline \multicolumn{5}{|l|}{ Grouped origin } \\
\hline East or Central Europe & 0.16 & 0.37 & 0.00 & 1.00 \\
\hline Middle East & 0.68 & 0.48 & 0.00 & 1.00 \\
\hline Africa & 0.15 & 0.36 & 0.00 & 1.00 \\
\hline Americas & 0.001 & 0.03 & 0.00 & 1.00 \\
\hline Stateless/unknown & 0.01 & 0.09 & 0.00 & 1.00 \\
\hline \multicolumn{5}{|l|}{ Region of residency } \\
\hline Municipality & 0.16 & 0.37 & 0.00 & 1.00 \\
\hline Zealand & 0.20 & 0.40 & 0.00 & 1.00 \\
\hline Southern Jutland & 0.26 & 0.44 & 0.00 & 1.00 \\
\hline Mid Jutland & 0.23 & 0.42 & 0.00 & 1.00 \\
\hline Northern Jutland & 0.15 & 0.36 & 0.00 & 1.00 \\
\hline $\begin{array}{l}\text { Ethnic concentration } \\
\text { (short-term) }\end{array}$ & 5.37 & 5.41 & 0.39 & 51.87 \\
\hline $\begin{array}{l}\text { Ethnic concentration } \\
\text { (medium-term) }\end{array}$ & 11.05 & 10.47 & 0.81 & 59.11 \\
\hline $\begin{array}{l}\text { Ethnic concentration } \\
\text { (long-term) }\end{array}$ & 15.36 & 12.94 & 1.31 & 71.80 \\
\hline $\begin{array}{l}\text { Welfare dependency } \\
\text { (short-term) }\end{array}$ & 44.46 & 7.29 & 24.75 & 71.32 \\
\hline $\begin{array}{l}\text { Welfare dependency } \\
\text { (medium-term) }\end{array}$ & 45.96 & 7.39 & 26.57 & 67.75 \\
\hline $\begin{array}{l}\text { Welfare dependency } \\
\text { (long-term) }\end{array}$ & 50.38 & 7.93 & 31.03 & 74.86 \\
\hline
\end{tabular}

Note: All variables are measured in the Danish administrative registers. 
Table A.3. RD Placebo Effect Estimates

\begin{tabular}{|c|c|c|c|c|c|c|c|c|c|c|}
\hline Model & (1) & (2) & (3) & (4) & $(5)$ & (6) & (7) & $(8)$ & (9) & (10) \\
\hline $\begin{array}{l}\text { Placebo } \\
\text { outcome }\end{array}$ & Age & Age sq. & Female & Married & Children & Africa & $\begin{array}{l}\text { Middle } \\
\text { East }\end{array}$ & $\begin{array}{c}\text { East/Cen- } \\
\text { tral } \\
\text { Europe }\end{array}$ & Americas & $\begin{array}{l}\text { Stateless/ } \\
\text { unknown }\end{array}$ \\
\hline $\begin{array}{l}\text { Treatment } \\
\text { effect }\end{array}$ & $\begin{array}{c}0.38 \\
(0.83)\end{array}$ & $\begin{array}{c}18.50 \\
(58.63)\end{array}$ & $\begin{array}{c}-0.28 * * * \\
(0.04)\end{array}$ & $\begin{array}{l}-0.01 \\
(0.05)\end{array}$ & $\begin{array}{l}-0.03 \\
(0.05)\end{array}$ & $\begin{array}{c}0.07 \\
(0.06)\end{array}$ & $\begin{array}{l}-0.00 \\
(0.07)\end{array}$ & $\begin{array}{l}-0.08 \\
(0.06)\end{array}$ & $\begin{array}{c}0.00 \\
(0.00)\end{array}$ & $\begin{array}{c}0.00 \\
(0.02)\end{array}$ \\
\hline $\begin{array}{l}\text { Residency } \\
\text { date } \\
\text { Treatment } \\
\text { x Resi- } \\
\text { dency date }\end{array}$ & $\begin{array}{c}-0.00 \\
(0.01) \\
0.01 \\
(0.01)\end{array}$ & $\begin{array}{c}-0.32 \\
(0.41) \\
0.88 \\
(0.54)\end{array}$ & $\begin{array}{c}0.00 * * * \\
(0.00) \\
-0.00 * * * \\
(0.00)\end{array}$ & $\begin{array}{c}0.00 \\
(0.00) \\
-0.00 \\
(0.00)\end{array}$ & $\begin{array}{c}0.00 \\
(0.00) \\
-0.00 \\
(0.00)\end{array}$ & $\begin{array}{c}0.00 * * * \\
(0.00) \\
-0.00 * * * \\
(0.00)\end{array}$ & $\begin{array}{c}-0.00 * * \\
(0.00) \\
0.00 * * * \\
(0.00)\end{array}$ & $\begin{array}{c}0.00 \\
(0.00) \\
-0.00 \\
(0.00)\end{array}$ & $\begin{array}{c}0.00 \\
(0.00) \\
-0.00 \\
(0.00)\end{array}$ & $\begin{array}{c}0.00 \\
(0.00) \\
-0.00 \\
(0.00)\end{array}$ \\
\hline Model & (11) & $(12)$ & (13) & (14) & (15) & (16) & $(17)$ & $(18)$ & (19) & $(20)$ \\
\hline $\begin{array}{l}\text { Placebo } \\
\text { outcome }\end{array}$ & $\begin{array}{l}\text { Schooling: } \\
\text { Level } 1\end{array}$ & $\begin{array}{l}\text { Schooling: } \\
\text { Level } 2\end{array}$ & $\begin{array}{l}\text { Schooling: } \\
\text { Level } 3\end{array}$ & $\begin{array}{l}\text { Schooling: } \\
\text { Level } 4\end{array}$ & $\begin{array}{l}\text { Schooling: } \\
\text { Level } 5\end{array}$ & $\begin{array}{c}\text { Region: } \\
\text { Municipal- } \\
\text { ity }\end{array}$ & $\begin{array}{l}\text { Region: } \\
\text { Zealand }\end{array}$ & $\begin{array}{l}\text { Region: } \\
\text { South Jut- } \\
\text { land }\end{array}$ & $\begin{array}{l}\text { Region: } \\
\text { Mid Jut- } \\
\text { land }\end{array}$ & $\begin{array}{l}\text { Region: } \\
\text { Northern } \\
\text { Jutland }\end{array}$ \\
\hline $\begin{array}{l}\text { Treatment } \\
\text { effect }\end{array}$ & $\begin{array}{l}-0.05 \\
(0.04) \\
\end{array}$ & $\begin{array}{c}0.01 \\
(0.04) \\
\end{array}$ & $\begin{array}{l}-0.00 \\
(0.05) \\
\end{array}$ & $\begin{array}{c}0.04 \\
(0.04) \\
\end{array}$ & $\begin{array}{l}-0.01 \\
(0.04) \\
\end{array}$ & $\begin{array}{c}0.09 \\
(0.05) \\
\end{array}$ & $\begin{array}{c}0.06 \\
(0.05) \\
\end{array}$ & $\begin{array}{l}-0.03 \\
(0.06) \\
\end{array}$ & $\begin{array}{l}-0.00 \\
(0.07) \\
\end{array}$ & $\begin{array}{l}-0.11 \\
(0.06) \\
\end{array}$ \\
\hline $\begin{array}{l}\text { Residency } \\
\text { date } \\
\text { Treatment } \\
\text { x Resi- } \\
\text { dency date }\end{array}$ & $\begin{array}{c}0.00 \\
(0.00) \\
-0.00 \\
(0.00)\end{array}$ & $\begin{array}{c}-0.00 \\
(0.00) \\
0.00 \\
(0.00)\end{array}$ & $\begin{array}{c}-0.00 \\
(0.00) \\
0.00 \\
(0.00)\end{array}$ & $\begin{array}{l}-0.00 \\
(0.00) \\
-0.00 \\
(0.00)\end{array}$ & $\begin{array}{c}-0.00 \\
(0.00) \\
0.00 \\
(0.00)\end{array}$ & $\begin{array}{c}-0.00 * \\
(0.00) \\
0.00 \\
(0.00)\end{array}$ & $\begin{array}{c}-0.00 \\
(0.00) \\
0.00 \\
(0.00)\end{array}$ & $\begin{array}{c}0.00 \\
(0.00) \\
-0.00 \\
(0.00)\end{array}$ & $\begin{array}{c}0.00 \\
(0.00) \\
-0.00 \\
(0.00)\end{array}$ & $\begin{array}{c}0.00 \\
(0.00) \\
-0.00 \\
(0.00)\end{array}$ \\
\hline $\begin{array}{l}\text { Observa- } \\
\text { tions }\end{array}$ & 2,324 & 2,324 & 2,324 & 2,324 & 2,324 & 2,324 & 2,324 & 2,324 & 2,324 & 2,324 \\
\hline
\end{tabular}

Note: Regression coefficients from local linear regression; standard errors clustered by first municipality in parentheses. $* P<0.05, * * P<$ $0.01, * * * P<0.001$. Kernel $=$ triangular. 
Figure A.1. RD Effect Estimates at Placebo Thresholds
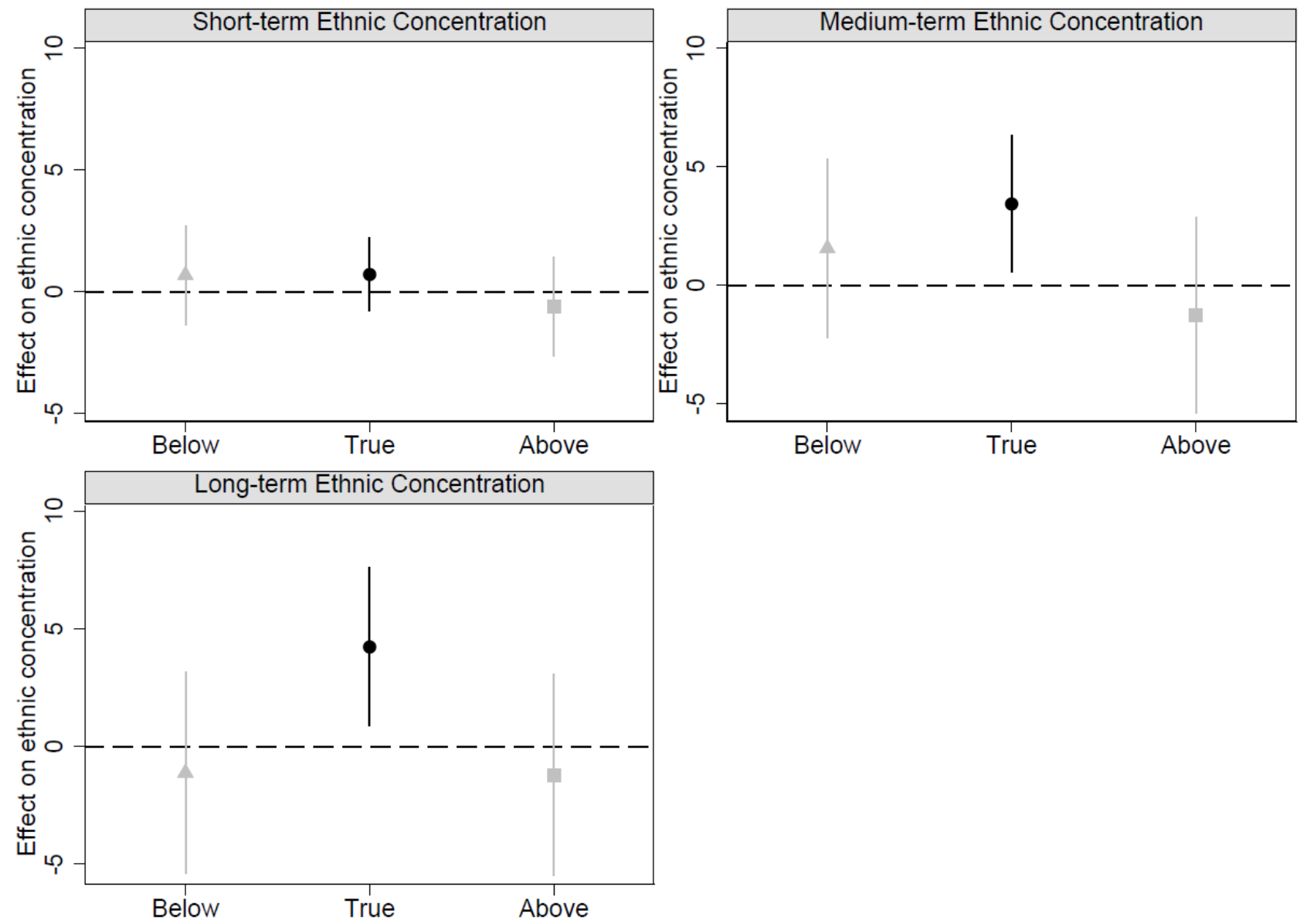

Note: Placebo effect estimates from the RD design. The grey filled triangles and squares show the estimated placebo treatment effect at (placebo) thresholds below and above the true threshold, respectively. The filled black circles show the effect estimate at the true threshold. Standard errors are clustered by municipality. The thick and thin lines show the $95 \%$ and $90 \%$ confidence intervals, respectively. Kernel = triangular. The placebo estimate below the threshold uses only observations below the threshold, and the placebo threshold is set at the median. The placebo estimate above the threshold uses only observations above the threshold, and the placebo threshold is set at the median. The plot shows that the observed jump in concentration, at the true threshold, indeed seems to be an effect of the start help reform and not an artefact of a jumpy relationship between the forcing variable and the outcome. Overall, this corroborates the key identifying assumption of local random assignment at threshold. 
Table A.4. Overall Effect of Lower Benefits on Ethnic Concentration

\begin{tabular}{lcccccc}
\hline \hline Model & $(1)$ & $(2)$ & $(3)$ & $(4)$ & $(5)$ & $(6)$ \\
\hline Outcome & Short-term & Short-term & $\begin{array}{c}\text { Medium- } \\
\text { term }\end{array}$ & $\begin{array}{c}\text { Medium- } \\
\text { term }\end{array}$ & $\begin{array}{c}\text { Long- } \\
\text { term }\end{array}$ & $\begin{array}{c}\text { Long- } \\
\text { term }\end{array}$ \\
\hline Treatment ef- & 0.64 & 0.15 & $3.01^{* *}$ & $2.61^{* *}$ & $3.95^{* *}$ & $\begin{array}{c}3.56^{* *} \\
(1.42)\end{array}$ \\
fect & $(0.64)$ & $(0.57)$ & $(1.25)$ & $(1.16)$ & $(1.53)$ & -0.01 \\
\hline Residency & -0.00 & 0.00 & -0.01 & -0.01 & -0.01 & -0.01 \\
date & $(0.00)$ & $(0.00)$ & $(0.01)$ & $(0.01)$ & $(0.01)$ & $(0.01)$ \\
Treatment $x$ & 0.00 & -0.00 & -0.01 & -0.01 & -0.01 & -0.01 \\
Residency & $(0.01)$ & $(0.01)$ & $(0.01)$ & $(0.01)$ & $(0.02)$ & $(0.01)$ \\
date & & & & & & \\
\hline Covariates & $\mathrm{x}$ & $\checkmark$ & $\mathrm{x}$ & $\checkmark$ & $\mathrm{V}$ & $\checkmark$ \\
\hline Observations & 2,324 & 2,324 & 2,324 & 2,324 & 2,324 & 2,324 \\
\hline \hline
\end{tabular}

Note: Regression coefficients from local linear regression; standard errors clustered by first municipality in parentheses. $* P<0.10, * * P<0.05, * * * P<0.01$. The outcome is coded as 0 or 100 such that the effect estimates are measured in percentage points. Kernel $=$ triangular.

Table A.5. RD Effect on Neighborhood Welfare Dependency

\begin{tabular}{lcccccc}
\hline \hline Model & $(1)$ & $(2)$ & $(3)$ & $(4)$ & $(5)$ & $(6)$ \\
\hline Outcome & Short-term & Short-term & $\begin{array}{c}\text { Medium- } \\
\text { term }\end{array}$ & $\begin{array}{c}\text { Medium- } \\
\text { term }\end{array}$ & $\begin{array}{c}\text { Long- } \\
\text { term }\end{array}$ & $\begin{array}{c}\text { Long- } \\
\text { term }\end{array}$ \\
\hline Treatment ef- & 0.54 & 0.95 & $1.99^{* *}$ & $2.45^{* * *}$ & $2.12^{* *}$ & $\begin{array}{c}2.56^{* *} \\
\text { fect }\end{array}$ \\
\hline Residency & $0.87)$ & $(0.83)$ & $(0.91)$ & $(0.85)$ & $(1.01)$ & $(1.01)$ \\
date & $(0.10)$ & 0.01 & 0.00 & -0.01 & -0.01 & -0.01 \\
Treatment $x$ & $-0.02^{*}$ & $(0.01)$ & $(0.01)$ & $(0.01)$ & $(0.01)$ & $(0.01)$ \\
Residency & $(0.01)$ & $(0.01)$ & $(0.01)$ & $(0.01)$ & $(0.01)$ & $(0.01)$ \\
date & & & & & & \\
\hline Covariates & $\mathrm{x}$ & $\checkmark$ & $\mathrm{x}$ & $\checkmark$ & $\mathrm{V}$ & $\checkmark$ \\
\hline Observations & 2,324 & 2,324 & 2,324 & 2,324 & 2,324 & 2,324 \\
\hline \hline
\end{tabular}

Note: Regression coefficients from local linear regression; standard errors clustered by first municipality in parentheses. ${ }^{*} P<0.10, * * P<0.05, * * * P<0.01$. The outcome is coded as 0 or 100 such that the effect estimates are measured in percentage points. Kernel $=$ triangular. 
Table A.6. Effect Heterogeneity

\begin{tabular}{|c|c|c|c|c|c|c|}
\hline Model & $\overline{(1)}$ & $(2)$ & (3) & (4) & $(5)$ & (6) \\
\hline Outcome & Short-term & Short-term & Short-term & Short-term & Short-term & Short-term \\
\hline Education subgroup & Low & Low & Medium & Medium & High & High \\
\hline Treatment effect & $\begin{array}{c}1.30 \\
(0.90)\end{array}$ & $\begin{array}{c}0.92 \\
(0.88)\end{array}$ & $\begin{array}{c}0.86 \\
(0.72)\end{array}$ & $\begin{array}{c}0.26 \\
(0.62)\end{array}$ & $\begin{array}{l}-1.16 \\
(1.24)\end{array}$ & $\begin{array}{l}-1.76 \\
(1.39)\end{array}$ \\
\hline Residency date & $\begin{array}{l}-0.01^{*} \\
(0.01)\end{array}$ & $\begin{array}{l}-0.01 \\
(0.01)\end{array}$ & $\begin{array}{l}-0.00 \\
(0.01)\end{array}$ & $\begin{array}{c}0.00 \\
(0.01)\end{array}$ & $\begin{array}{c}0.01 \\
(0.01)\end{array}$ & $\begin{array}{c}0.02 \\
(0.01)\end{array}$ \\
\hline $\begin{array}{l}\text { Treatment } x \text { Resi- } \\
\text { dency date }\end{array}$ & $\begin{array}{c}0.01 \\
(0.01)\end{array}$ & $\begin{array}{c}0.01 \\
(0.01)\end{array}$ & $\begin{array}{l}-0.00 \\
(0.01)\end{array}$ & $\begin{array}{l}-0.00 \\
(0.01)\end{array}$ & $\begin{array}{l}-0.01 \\
(0.01)\end{array}$ & $\begin{array}{l}-0.02 \\
(0.01)\end{array}$ \\
\hline Covariates & $\mathrm{x}$ & $\checkmark$ & $\mathrm{x}$ & $\checkmark$ & $\mathrm{x}$ & $\checkmark$ \\
\hline Observations & 914 & 914 & 944 & 944 & 466 & 466 \\
\hline Model & (7) & (8) & (9) & (10) & (11) & (12) \\
\hline Outcome & $\begin{array}{l}\text { Medium- } \\
\text { term }\end{array}$ & $\begin{array}{l}\text { Medium- } \\
\text { term }\end{array}$ & $\begin{array}{l}\text { Medium- } \\
\text { term }\end{array}$ & $\begin{array}{l}\text { Medium- } \\
\text { term }\end{array}$ & $\begin{array}{l}\text { Medium- } \\
\text { term }\end{array}$ & $\begin{array}{c}\text { Medium- } \\
\text { term }\end{array}$ \\
\hline Education subgroup & Low & Low & Medium & Medium & High & High \\
\hline Treatment effect & $\begin{array}{l}4.72 * * \\
(2.29)\end{array}$ & $\begin{array}{l}4.28 * * \\
(2.10)\end{array}$ & $\begin{array}{l}1.50 \\
(1.38)\end{array}$ & $\begin{array}{l}2.70 \\
(2.14)\end{array}$ & $\begin{array}{c}3.04 \\
(2.52) \\
\end{array}$ & $\begin{array}{c}1.98 \\
(2.81)\end{array}$ \\
\hline Residency date & $\begin{array}{l}-0.01 \\
(0.01)\end{array}$ & $\begin{array}{l}-0.01 \\
(0.01)\end{array}$ & $\begin{array}{l}-0.01 \\
(0.01)\end{array}$ & $\begin{array}{l}-0.03 \\
(0.02)\end{array}$ & $\begin{array}{l}-0.01 \\
(0.02)\end{array}$ & $\begin{array}{l}-0.01 \\
(0.02)\end{array}$ \\
\hline $\begin{array}{l}\text { Treatment } x \text { Resi- } \\
\text { dency date }\end{array}$ & $\begin{array}{l}-0.02 \\
(0.02)\end{array}$ & $\begin{array}{l}-0.02 \\
(0.02)\end{array}$ & $\begin{array}{l}-0.01 \\
(0.02)\end{array}$ & $\begin{array}{c}0.02 \\
(0.02) \\
\end{array}$ & $\begin{array}{l}-0.01 \\
(0.03)\end{array}$ & $\begin{array}{l}-0.01 \\
(0.03)\end{array}$ \\
\hline Covariates & $\mathrm{x}$ & $\checkmark$ & $\mathrm{x}$ & $\checkmark$ & $\mathrm{x}$ & $\checkmark$ \\
\hline Observations & 914 & 914 & 944 & 944 & 466 & 466 \\
\hline Model & (13) & (14) & (15) & (16) & (17) & (18) \\
\hline Outcome & Long-term & Long-term & Long-term & Long-term & Long-term & Long-term \\
\hline Education subgroup & Low & Low & Medium & Medium & High & High \\
\hline Treatment effect & $\begin{array}{l}6.90 * * \\
(2.74)\end{array}$ & $\begin{array}{l}6.13 * * \\
(2.57)\end{array}$ & $\begin{array}{l}1.96 \\
(1.76)\end{array}$ & $\begin{array}{c}1.87 \\
(1.71)\end{array}$ & $\begin{array}{c}3.04 \\
(2.68)\end{array}$ & $\begin{array}{c}2.14 \\
(2.88)\end{array}$ \\
\hline Residency date & $\begin{array}{l}-0.01 \\
(0.02)\end{array}$ & $\begin{array}{l}-0.01 \\
(0.02)\end{array}$ & $\begin{array}{l}-0.01 \\
(0.01)\end{array}$ & $\begin{array}{l}-0.02^{*} \\
(0.01)\end{array}$ & $\begin{array}{l}-0.00 \\
(0.02)\end{array}$ & $\begin{array}{l}-0.00 \\
(0.02)\end{array}$ \\
\hline $\begin{array}{l}\text { Treatment x Resi- } \\
\text { dency date }\end{array}$ & $\begin{array}{l}-0.04 \\
(0.03)\end{array}$ & $\begin{array}{l}-0.03 \\
(0.02)\end{array}$ & $\begin{array}{c}0.01 \\
(0.02)\end{array}$ & $\begin{array}{c}0.02 \\
(0.02)\end{array}$ & $\begin{array}{l}-0.02 \\
(0.03)\end{array}$ & $\begin{array}{l}-0.02 \\
(0.03)\end{array}$ \\
\hline Covariates & $\mathrm{x}$ & $\checkmark$ & $\mathrm{x}$ & $\checkmark$ & $\mathrm{x}$ & $\checkmark$ \\
\hline Observations & 914 & 914 & 944 & 944 & 466 & 466 \\
\hline
\end{tabular}

Note: Regression coefficients from local linear regression; standard errors clustered by first municipality in parentheses. $* P<0.10, * * P<0.05, * * * P<0.01$. The outcome is coded as 0 or 100 such that the effect estimates are measured in percentage points. Kernel $=$ triangular. 
Figure A.2. Graphical Results
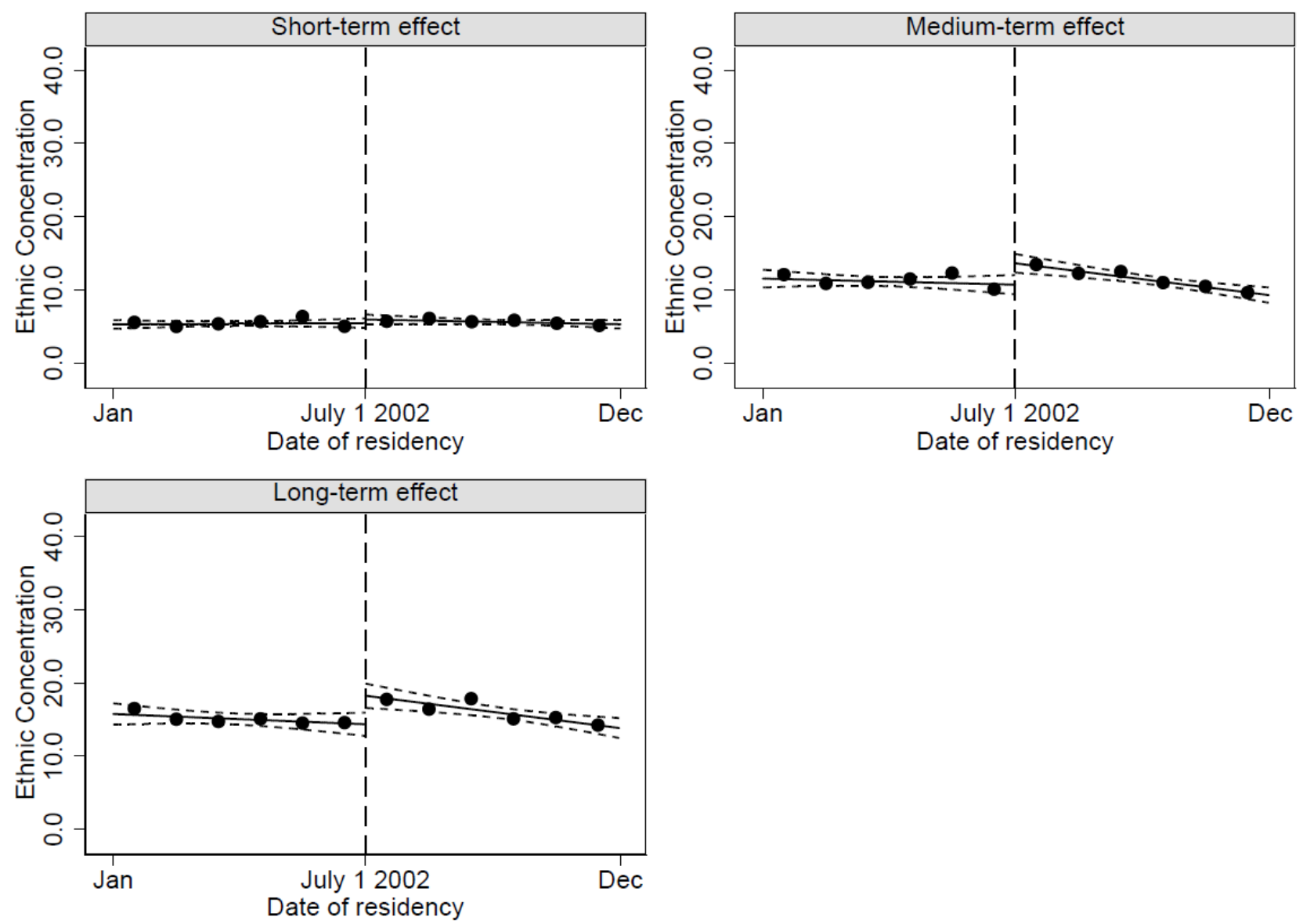

Note: Figure A.3 displays the results of the RD design graphically. Consistent with the marginal differences plotted in Figure 2, these analyses demonstrates that there is no jumps in the ethnic concentration in the short-term. To the contrary, there are clear jumps in the concentration in the medium- and long-term. 
Figure A.3. Sensitivity over Different Bandwidths
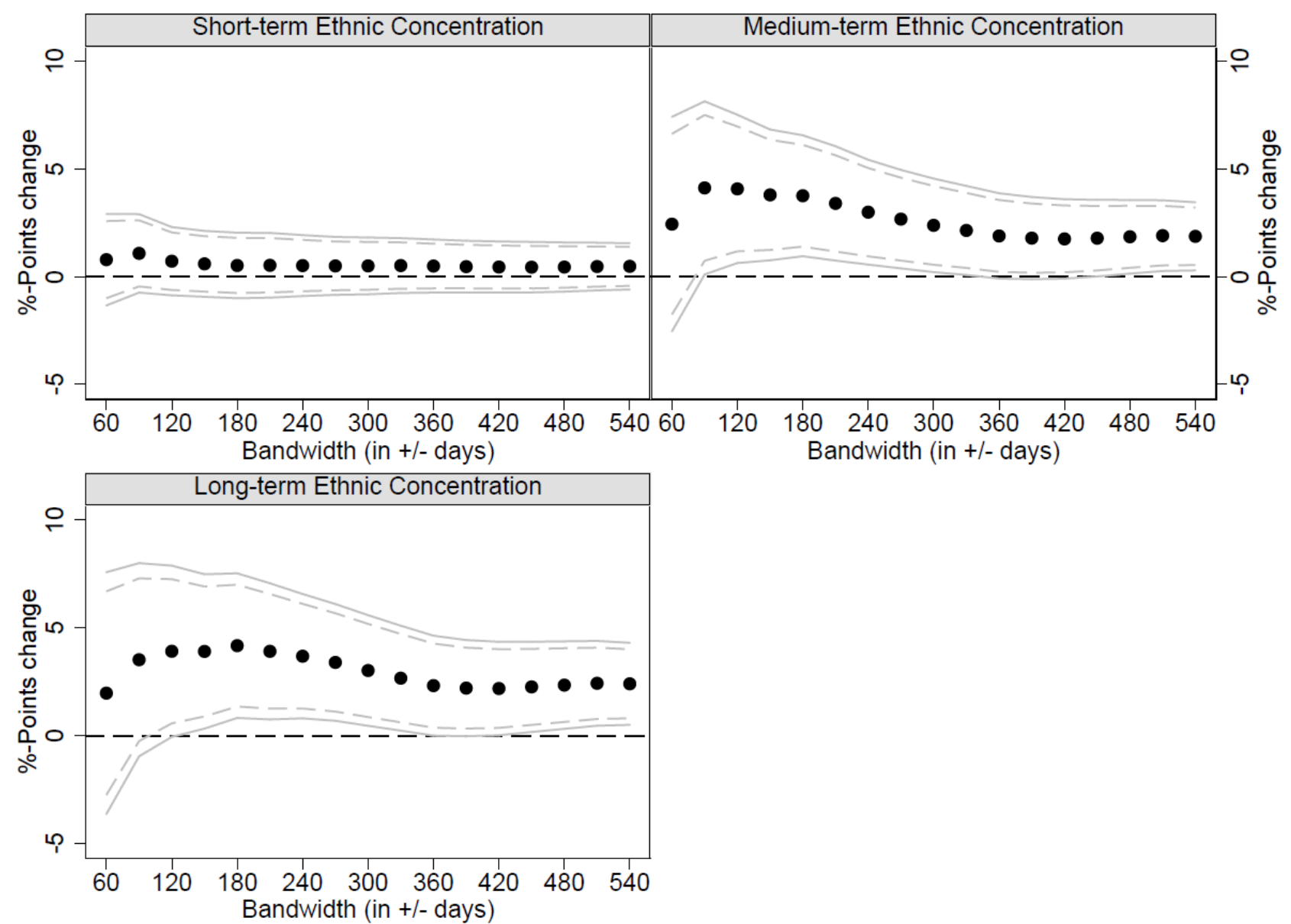

Note: The figure shows the estimated effect of start help on the outcomes as a function of the bandwidth for the RD models. Dots represent the point estimates based on the sample within the corresponding value of the forcing variable. Standard error clustered by municipality. The grey solid and dashed lines show the $90 \%$ and $95 \%$ confidence intervals, respectively. Kernel $=$ triangular. 
Table A.7. Overall RD effects using local quadratic specifications

\begin{tabular}{|c|c|c|c|c|c|c|}
\hline Model & $(1)$ & (2) & (3) & $(4)$ & $(5)$ & $(6)$ \\
\hline Outcome & Short-term & Short-term & $\begin{array}{l}\text { Medium- } \\
\text { term }\end{array}$ & $\begin{array}{c}\text { Medium- } \\
\text { term }\end{array}$ & $\begin{array}{c}\text { Long- } \\
\text { term }\end{array}$ & $\begin{array}{c}\text { Long- } \\
\text { term }\end{array}$ \\
\hline $\begin{array}{l}\text { Treatment ef- } \\
\text { fect }\end{array}$ & $\begin{array}{c}1.01 \\
(0.76) \\
\end{array}$ & $\begin{array}{c}0.44 \\
(0.70) \\
\end{array}$ & $\begin{array}{l}3.13^{*} \\
(1.77)\end{array}$ & $\begin{array}{l}3.08^{*} \\
(1.62)\end{array}$ & $\begin{array}{l}3.56^{*} \\
(2.01)\end{array}$ & $\begin{array}{l}3.41 * \\
(1.83)\end{array}$ \\
\hline Covariates & $x$ & $\checkmark$ & $x$ & $\checkmark$ & $x$ & $\checkmark$ \\
\hline Observations & 2,324 & 2,324 & 2,324 & 2,324 & 2,324 & 2,324 \\
\hline
\end{tabular}


Figure A.4. Integration Policies in a Comparative Perspective: Migrant Integration Policy Index

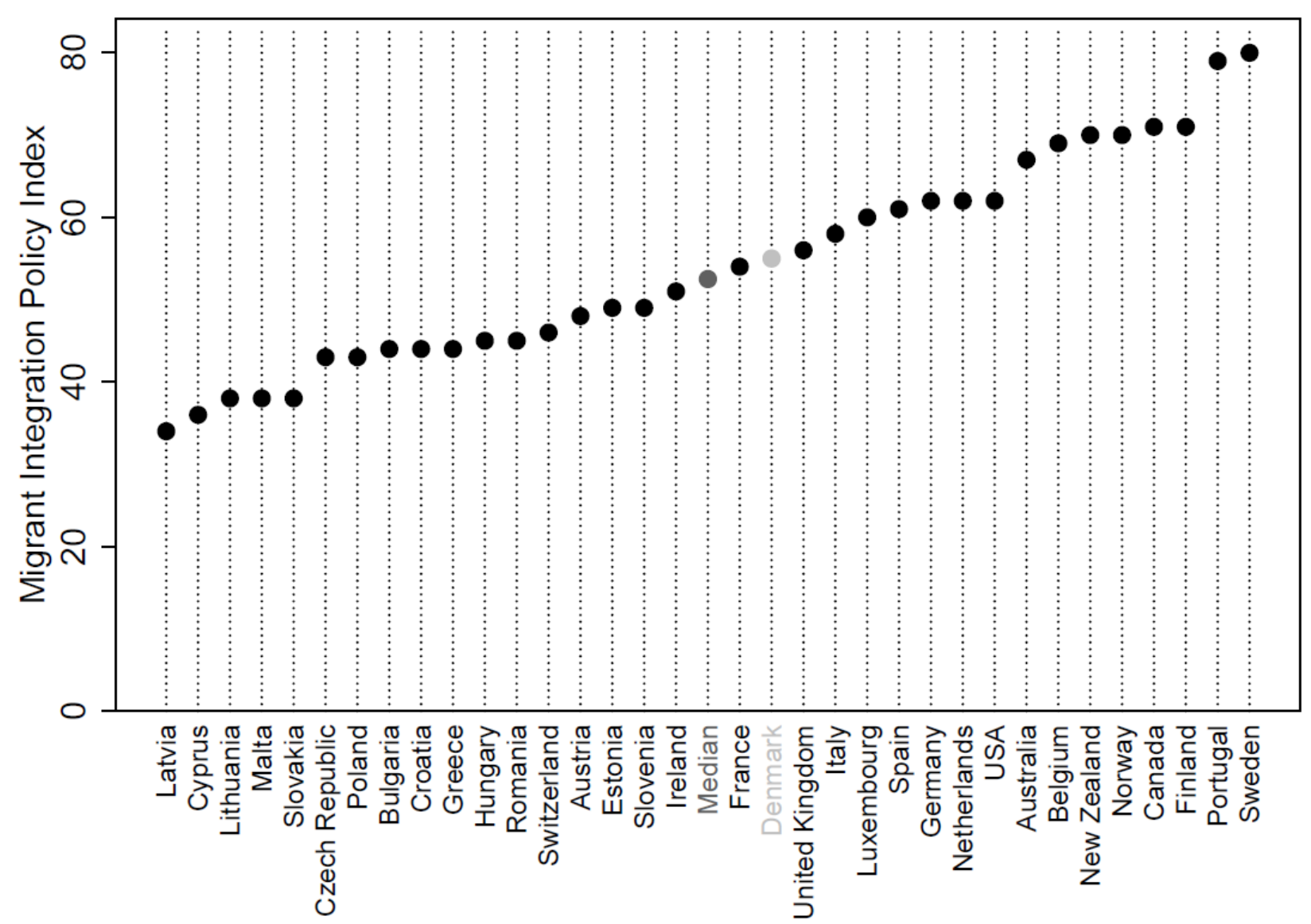

Note: MIPEX measures a country's integration policies based on 167 integration policy indicators where 0 represents as unequal policies as possible and 100 as equal as possible. 